\title{
Doping effects on electrical and dynamical characteristics of GaAs / AlGaAs quantum cascade
} laser

\author{
Dr. Erada A. Al-Dabbagh \\ Department of Physics \\ College Of Science \\ University of Mosul
}

Received

24 / 07 / 2007
\& Dr. Ragheed M. Ibrahim

Department of Physics

College of Education

University of Mosul

Accepted

03 / 12 / 2007

\section{|لاdan}

قم في هذا البحث التحللي الظري لتأثير كثلفة الظعيم على خ ـواص خ ـرج اللي -زر

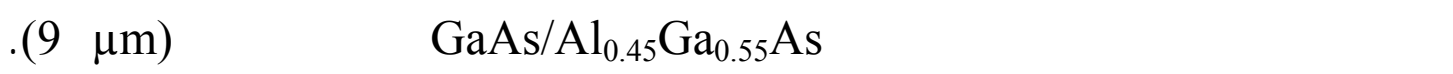

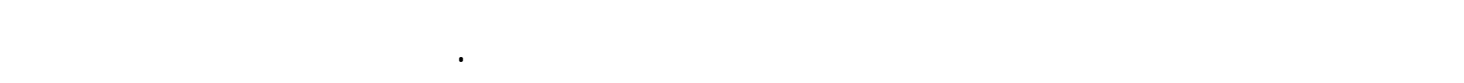

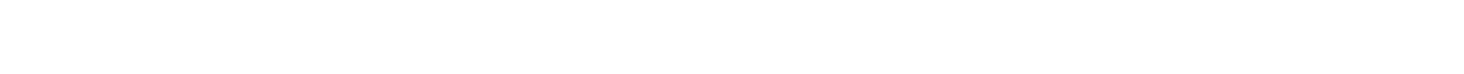

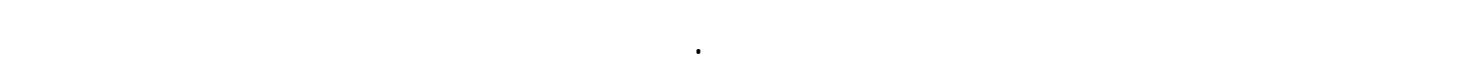
زحف في الطول الموجي نحو الأطول الموجية الأقصر فضلا عن القصان في قيمة الـ ـربح. كذك وجد من خلل النتائج ان مدى تيار التشغل قبل الوصول إلى اله مطقة المقاومة الفاضلية اللسالبة يقل بزيادة مستويت كثثلة الظعيم.

\begin{abstract}
A theoretical analysis of the doping density level influence on the output characteristics of $\mathrm{GaAs} / \mathrm{Al}_{0.45} \mathrm{Ga}_{0.55} \mathrm{As}$ triple quantum well QCL emitting at $(\lambda=9 \mu \mathrm{m})$ is presented. The employed theoretical model was based on Schrodinger equation analysis. Six different doping density levels, have been used in this study to explain doping density level influence on model gain as a function of wavelength and negative differential resistance (NDR). In the conventionally employed high doping regime, the wavelength shift to the shorter wavelength furthermore to decrease of the peak gain value with doping density level increase has been observed. The available current range before the occurrence of the NDR reduced when the doping density level decrease was found.
\end{abstract}




\section{1- Introduction}

The idea of electrically pumped intersubband lasers or quantum cascade lasers (QCLs) as unipolar semiconductor devices utilizing intersubband transitions in a repetition of identical coupled multiquantum-well structures was pioneered by Kazarinov and Suris. ${ }^{[1]}$ However, more than 20 years passed until the experimental realization was demonstrated by Faist et al. at Bell Laboratories on an InP substrate. ${ }^{[2]}$ Since then tremendous progress in QCL research has resulted in bidirectional, multiwavelength, ${ }^{[3]}$ ultrabroadband, ${ }^{[4]}$ above room temperature continuous-wave $\mathrm{CW}$ operation, ${ }^{[5]}$ sum-frequency and higher order harmonic generation, ${ }^{[6]}$ and fully integrated electrically pumped Raman lasers. Moreover, laser operation has been reported on other material systems, i.e., AlGaAs on a GaAs substrate ${ }^{[7]}$ and $\mathrm{Al}(\mathrm{Ga}) \mathrm{Sb}$ on InAs. ${ }^{[8]}$ Devices with Sb-containing barriers on both InAs substrate ${ }^{[9]}$ as well as on InP substrate ${ }^{[10]}$ are promising for either increasing the electron confinement or reducing the emission wavelength, and above room temperature pulsed operation on both substrates were recently reported. ${ }^{[9]}$

Since the realization ${ }^{[7]}$ of the GaAs-based quantum cascade laser, an impressive extension of the attainable infrared frequency range has been achieved and can be operated at wavelengths as long as $160 \mu \mathrm{m} .{ }^{[7]}$ The design of QCLs based on GaAs/AlGaAs can be made very flexible by varying the $\mathrm{Al}$ content due to naturally occurring near lattice matched material system across the full range of $\mathrm{Al}$ contents ${ }^{[11]}$. Hence, following the first terahertz QCL, several laser designs based on $15 \% \mathrm{Al}$ content in the barriers were presented, approaching high temperature pulsed operation $(137 \mathrm{~K})$ and above or close to liquid nitrogen temperature $\mathrm{CW}$ operation $^{[12]}$.

GaAs-based QCLs emitting in the midinfrared spectral region have so far used $\mathrm{Al}$ contents of $33 \%,{ }^{[7]} 45 \%,{ }^{[13]}$ and $100 \%,{ }^{[10]}$ respectively. Pulsed room temperature operation has been reported only for designs with $45 \% \mathrm{Al}$ content ${ }^{[13]}$ except for one design employing AlAs barriers and monolayers of InAs deposited at the antinode of the electron wave functions in order to improve the electron confinement. Achieving $\mathrm{CW}$ operation in midinfrared GaAsbased QCLs is a very challenging task due to the relatively high threshold current densities ${ }^{[14]}$.

The doping level in the active region is an important parameter with particular influence on the dynamical working range of QCLs. Until now, very few experimental investigations have been presented including the influence of the injector doping of InP-based ${ }^{[15]}$ and GaAs- based ${ }^{[16]}$ QCL threshold current. 
Due to the superior device performance of midinfrared devices with $45 \% \mathrm{Al}$ content there is a demand for a comprehensive experimental and theoretical analysis of these designs.

In this work, we report such an investigation of $\mathrm{GaAs} / \mathrm{Al}_{0.45} \mathrm{Ga}_{0.55} \mathrm{As}$ triple quantum well QCL emitting at $(\lambda=9 \mu \mathrm{m})$ $\operatorname{design}^{[17]}$ in which the influence of the doping density on the carrier dynamics and electrical characteristics are analyzed. It has been pointed out that the doping density is one of key parameters in QCL optimization. The electron transport in the $(\lambda=9 \mu \mathrm{m}) \mathrm{GaAs} / \mathrm{Al}_{0.45} \mathrm{Ga}_{0.55} \mathrm{As}$ QCL reported in Ref.[17] was simulated, and the onoequilibrium distribution over subbands for $(\mathrm{N})$ injector doping densities was calculated.

\section{2- Proposed Device Model}

The proposed structure is illustrated schematically in Fig.(1), where the notation for identifying the energy levels and carrier population in those levels were established. Subscripts identify the quantum well number, superscripts identify the energy subband level. The laser is electrically pumped, an electron enters the structure by tunneling through the first barrier $B_{1}$ to the energy level $E_{1}$ in the first quantum well $\mathrm{W}_{1}$. Tunneling through to $\mathrm{E}_{2}{ }^{(2)}$ in the second quantum well $\mathrm{W}_{2}$ it then makes a vertical transition to $\mathrm{E}_{2}{ }^{(1)}$, after which rapidly tunnels to $\mathrm{E}_{3}$ in the third quantum well $\mathrm{W}_{3}$ and escapes out of the structure.

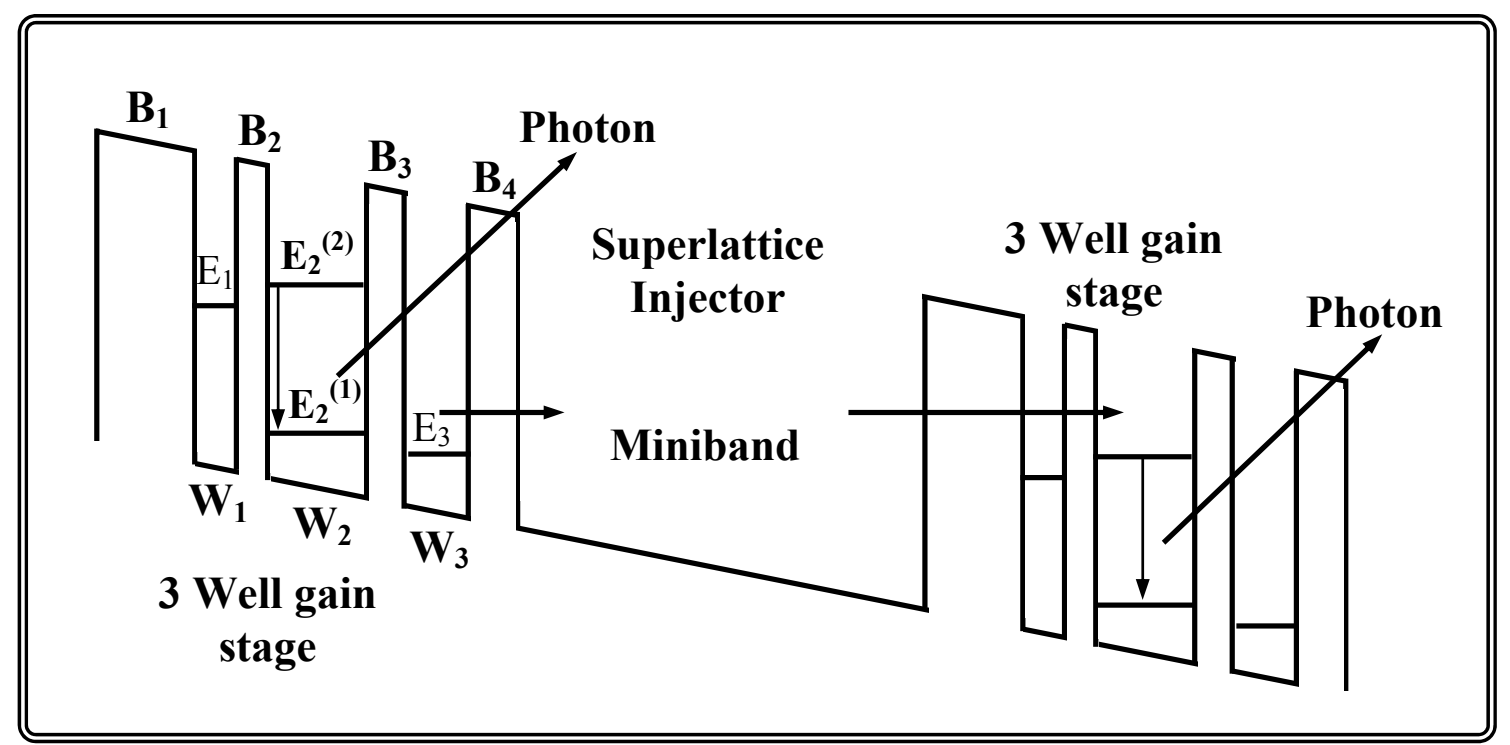

Fig.(1): Schematic conduction-band diagram of the proposal structure biased to an appropriating voltage.

In order to achieve this, the four lowest energy levels are such that one each localized in $\mathrm{W}_{1}\left(\mathrm{E}_{1}\right)$ and the other localized in $\mathrm{W}_{3}\left(\mathrm{E}_{3}\right)$, and two 
localized in $\mathrm{W}_{2}\left(\mathrm{E}_{2}{ }^{(1)}\right.$ and $\left.\mathrm{E}_{2}{ }^{(2)}\right)$ when the structure is in a uniform condition. At an appropriate bias of operating voltage, coupling occurs between $\mathrm{E}_{1}$ and $\mathrm{E}_{2}{ }^{(2)}$, and between $\mathrm{E}_{2}{ }^{(1)}$ and $\mathrm{E}_{3}$. The dimension of the proposal structure is illustrated in Table (1).

As the lasing transition occurs in $\mathrm{W}_{2}$ the lifetime corresponding to $\mathrm{E}_{2}{ }^{(2)}$ should be longer than that of $\mathrm{E}_{2}{ }^{(1)}$. We also require a lasing wavelength of normally $(9 \mu \mathrm{m})$ so the lasing transition should have an energy no more or less than $(137 \mathrm{meV})$. In order to achieve this, we should apply a suitable bias voltage to the structure, such that the separation between the two energy levels involved in the transition is: $\mathrm{E}_{2}^{(2)}-\mathrm{E}_{2}^{(1)}=137 \mathrm{meV}=\Delta \mathrm{E}$

The corresponding laser transition energy $(\Delta \mathrm{E})$ or $\left(\mathrm{E}_{32}\right)$ can be early varied if a different emission wavelength is desired. The second well width has to be adjusted as ${ }^{[1}$ :

$\mathrm{L}_{\mathrm{w}}=\sqrt{\frac{\left(\mathrm{n}_{2}^{(2)}-\mathrm{n}_{2}^{(1)}\right) \mathrm{h}^{2}}{8 \mathrm{~m}^{*} \Delta \mathrm{E}}}$

Where $\left(\mathrm{L}_{\mathrm{w}}\right)$ is the second well width, (h) is the blank constant, $\left(\mathrm{n}_{2}^{(2)}\right)$ is the quantum number of the upper energy state in the second quantum well, $\left(\mathrm{n}_{2}^{(1)}\right)$ is the quantum number of the lower energy state in the second quantum well, $(\Delta \mathrm{E})$ is the transition energy, and $\left(\mathrm{m}^{*}\right)$ is the electron effective mass. The device is formed by a triple-well structure using GaAs $/ \mathrm{Al}_{0.45} \mathrm{Ga}_{0.55} \mathrm{As}$ material. This structure is essentially a threelevel system $\left(E_{3}, E_{2} \& E_{1}\right)$ which is required for any laser, electron can be reused many times. Consequently, many identical triple-well modules can be cascade-connected, and the emission power and the mode confinement factor can be increased substantially. Due to translational symmetry, design analysis needs to focus only on one module, provided there are no global space charges and high-field domains ${ }^{[l}$. Under the designed bias, the ground state $\mathrm{E}_{1}$ of a previous module is aligned with $\mathrm{E}_{2}{ }^{(2)}\left[\mathrm{I}\right.$. Thus the upper subband $\mathrm{E}_{2}{ }^{(2)}$ can be selectively populated through resonant tunneling. The energy separation between $E_{2}^{(1)}$ and $E_{3}$ was greater than the longitudinal optical phonon (LO), the phonon energy is $(36 \mathrm{meV})$ in GaAs. Once energetically allowed, the very fast LO-phonon scattering will rapidly depopulate the $\mathrm{E}_{2}{ }^{(1)}$ level and establish a population inversion between $\mathrm{E}_{2}{ }^{(2)}$ and $\mathrm{E}_{2}{ }^{(1)}$. In general, the bandgap $\mathrm{E}_{\mathrm{g}}$ is given as:

$\mathrm{E}_{\mathrm{g}}=(1.426+1.246 \mathrm{x}) \mathrm{eV}$

The electron effective mass is :

$\mathrm{m}_{\mathrm{e}}^{*}=(0.067+0.083 \mathrm{x}) \mathrm{m}$ 
Where $\mathrm{m}$ is the free electron mass. The heavy-hole effective mass is, $\mathrm{m}_{\mathrm{h}}^{*}=(0.62+0.14 \mathrm{x}) \mathrm{m}$

Table (1): The levels energy, the well and barrier width of our proposal

\begin{tabular}{|c||c||c|c|}
\hline Energy Level & Location (meV) & Well Width (nm) & Barrier Width(nm) \\
\hline $\mathrm{E}_{1}$ & 240 & 4.8 & 10 \\
\hline $\mathrm{E}_{2}{ }^{(2)}$ & 250 & 14 & 3 \\
\hline $\mathrm{E}_{2}{ }^{(1)}$ & 113 & 14 & 6 \\
\hline $\mathrm{E}_{3}$ & 73.73 & 8.7 & 7 \\
\hline
\end{tabular}

\section{3- The model gain mechanisms}

In this paper, we present a study of the gain characteristics of GaAs-based QCL. Contrary to conventional interband diode lasers, in a QCL most of the physical properties of the active medium can be artificially tailored by an appropriate quantum design. Indeed, one can change the emission wavelength and also substantially modify the magnitude of optical phonon-limited relaxation rates by adjusting the conduction band edge discontinuity together with the thickness and the number of layers ${ }^{[18]}$. The drawback of this large design freedom is the number of relevant parameters that have to be taken into account to correctly predict intersubband carrier dynamics in multi-quantum well structures under strong applied electric field ${ }^{[19]}$. To this end, the possibility of monitoring the gain spectrum constitutes an invaluable tool, which provides direct information concerning the electronic population in the various subbands as a function of the applied bias (i.e., of the current density's and may suggest the appropriate modifications to introduce in active region design).

Now, we turn to evaluate the lasing performance of the QCL, by calculating the active region gain at different doping density levels. Fig.(2) shows the calculated model gain as a function of the wavelength for different doping densities level in the range between $\left(1.5 \times 10^{23}-2 \times 10^{23}\right) \mathrm{cm}^{-3}$. Accordingly the gain was increased until reaching the maximum value at the wavelength equal to the photon wavelength. Also this figure means that the gain is not sharp line at the photon energy $(\hbar \omega)$ due to the transition energy added to the model gain.

Booth Fig.(3) and Fig.(4) show wavelength and the peaks of model gain as a function of doping density. Fig.(3) gives the inverse dependence on the doping density, which means that, the wavelength shift is clearly to 
the visible and short wavelength with increasing of the doping density. Also Fig.(4) shows the inverse dependence on the doping density, i.e., the peaks gain were decreased of many values of doping density. Or, we can say that, the peak model of gain is transfer from one wavelength to another by changing the range of doping density. Accordingly, one can change the wavelength not only by variation the well thickness, but also one can get the available wavelength by changing the doping density.

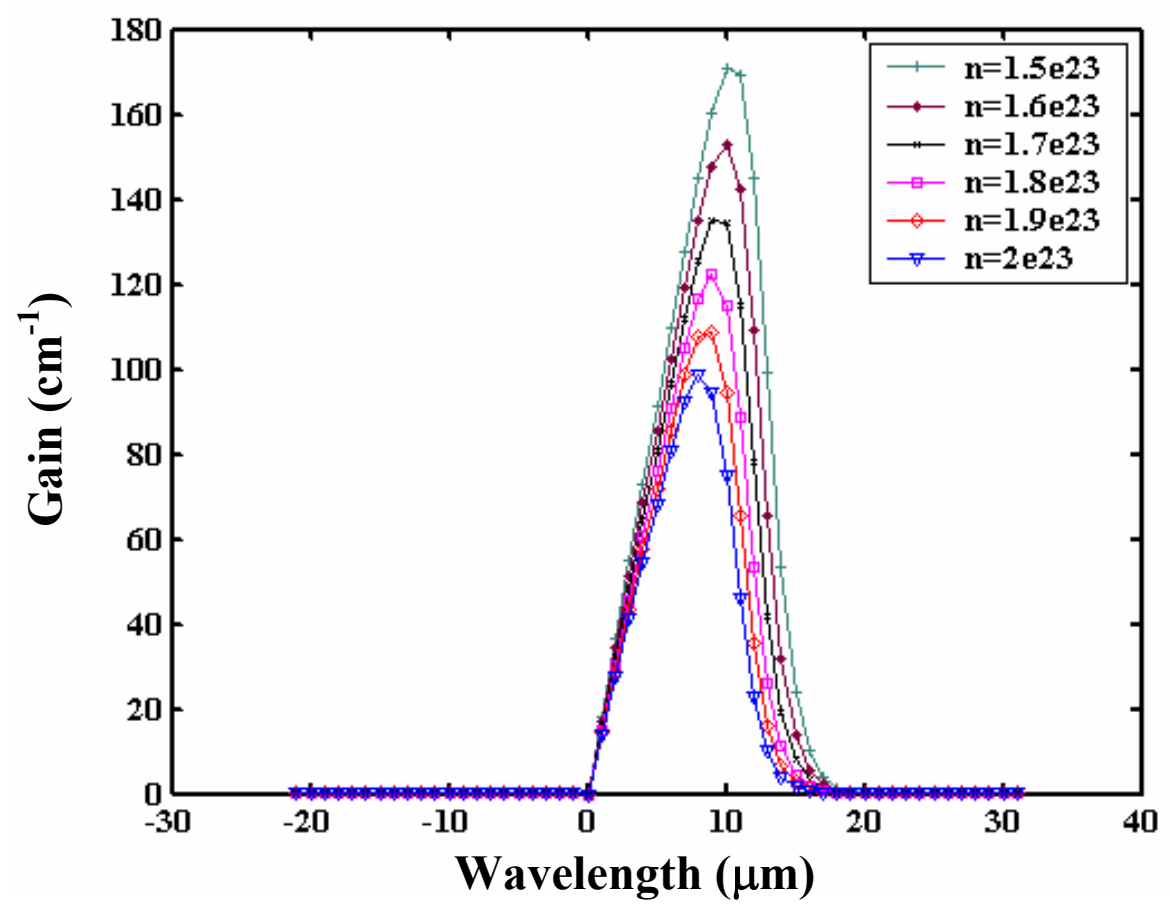

Fig.(2): Gain as a function of wavelength for a range of doping density

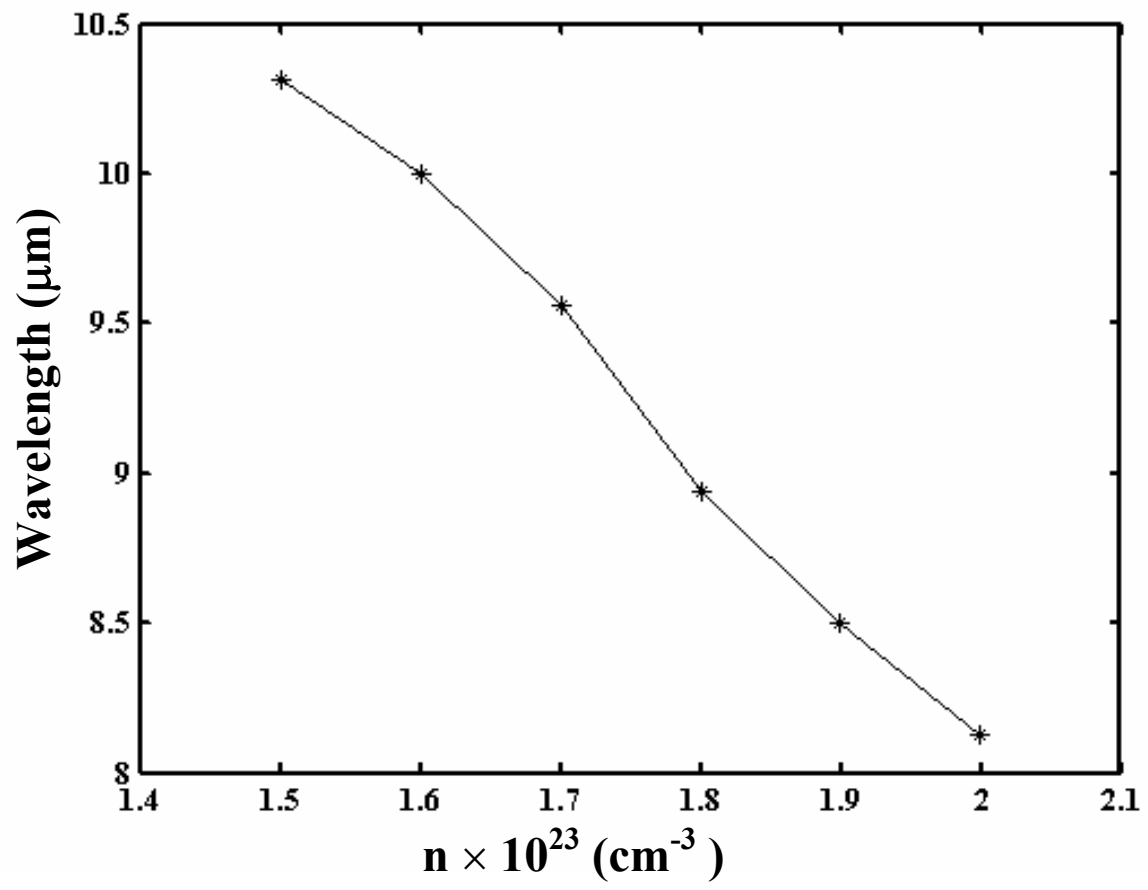

Fig.(3): Wavelength emission as a function of doping density 


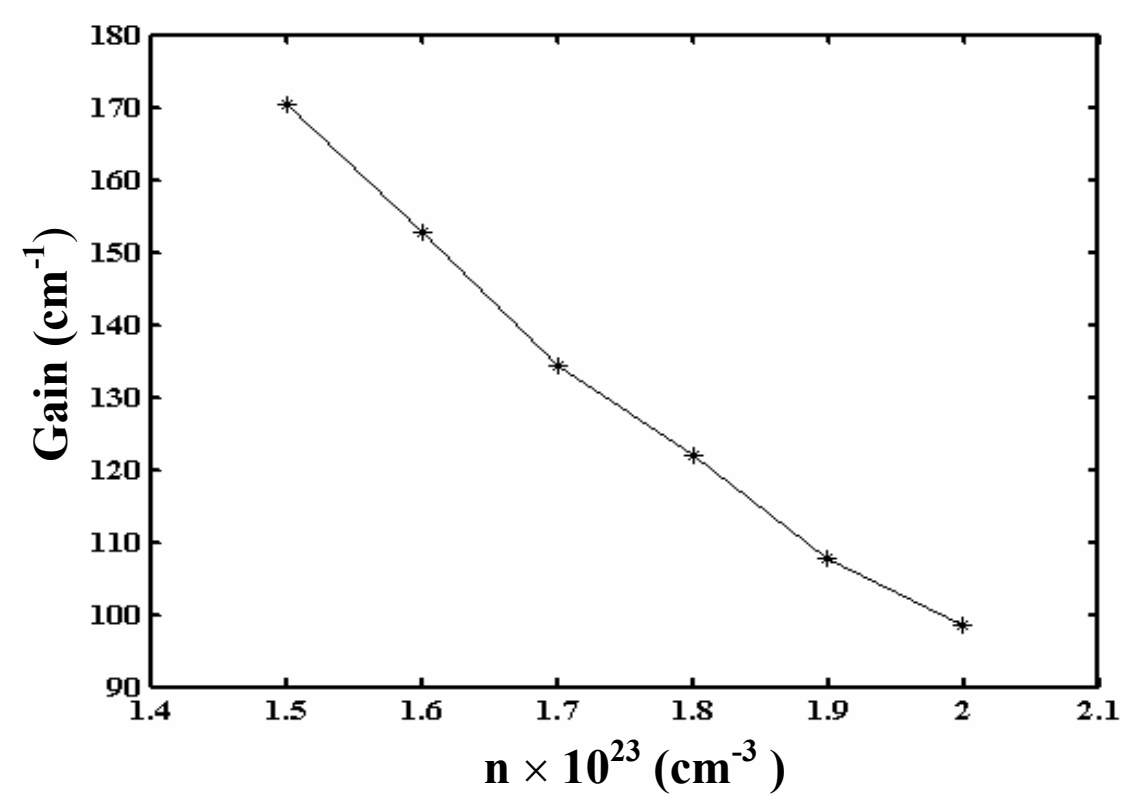

Fig.(4) Gain emission as a function of doping density

\section{4- Negative Differential Resistance}

It is important to note that, even though devices with the lowest temperature dependence of threshold current density $\left(\mathrm{J}_{\mathrm{th}}\right)$ have been demonstrated with GaAs-AlGaAs lasers, these structures are limited by negative differential resistance (NDR) effect. The lasers grown using an GaAs- $\mathrm{Al}_{0.45} \mathrm{Ga}_{0.55} \mathrm{As}$ heterostructure are at present the best compromise between effective carrier confinement and larger operating range with this $\mathrm{Al}$ composition GaAs lasers operate routinely at room temperature. Fig.(5) shows the V-I characteristics of the laser with different values of doping density. The abrupt increase in voltage $(\mathrm{V})$ is due to the breaking of the resonant alignment of the injector ground state with the $(n=3)$ exited state. This leads to a fall of the injection efficiency and, while the device enters a regime of negative differential resistance, laser action is last. This process occurs at a critical voltage $V_{\text {res }}$ and with good approximation we can assume that $\mathrm{V}_{\text {res }}$ is constant at a given value of doping density. However, the NDR region becomes less pronounced as the $\mathrm{Al}$ concentration is reduced, due to the leakage current that helps to maintain current flow through the structure even though the injection efficiency into the $(\mathrm{n}=3)$ state is lost.

Also, Fig.(5) shows the effect of doping density on the NDR. It is clear that the NDR decreased when the doping density increased and visa a versa. After taking the linear part of these curves in our consideration in order to found the aproparate doping density which makes the resistance approach zero, we found that. 


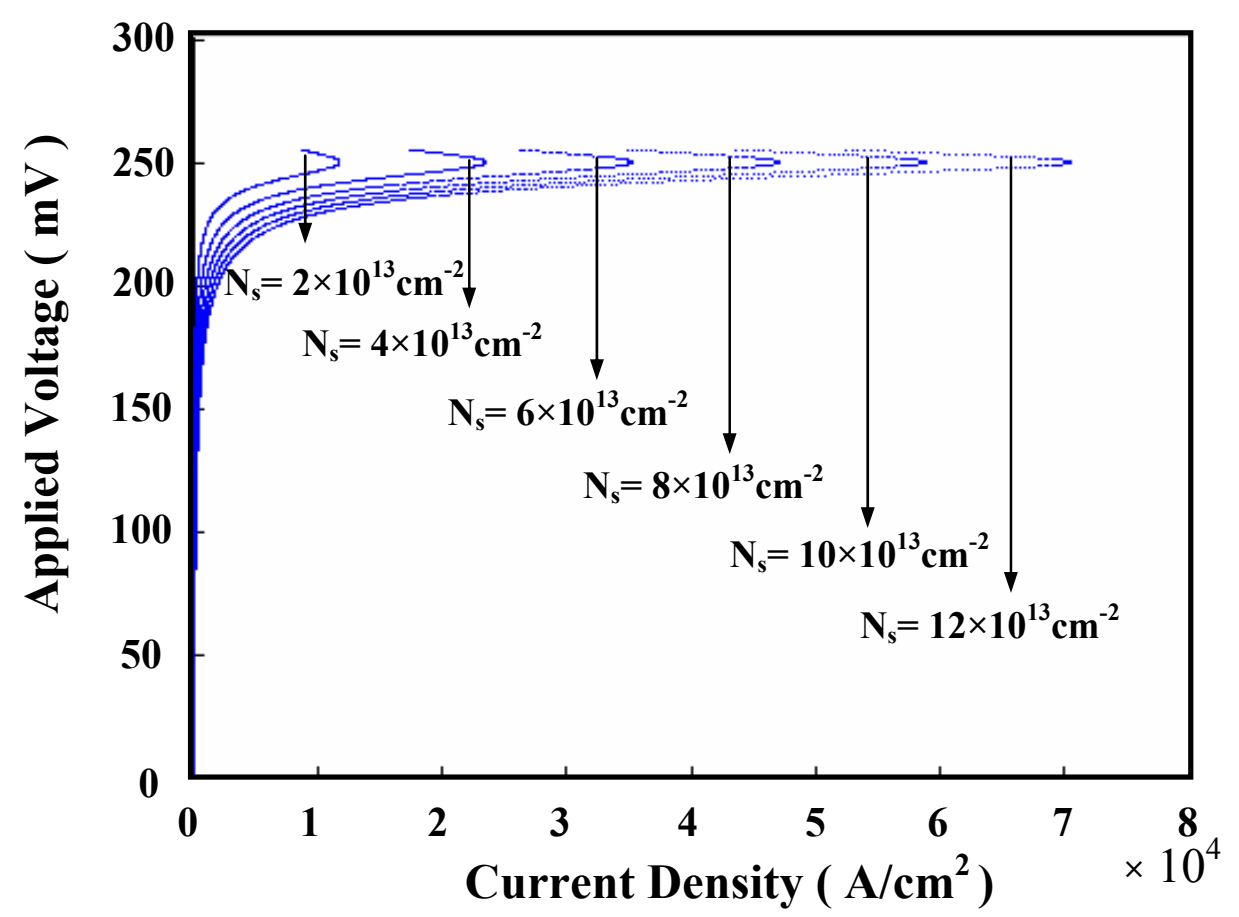

Fig.(5): The negative differential resistance effect as a function of doping density

\section{5- Conclusions}

In conclusion, we have reported a detailed study of the impact of doping densities on the performance of $\mathrm{GaAs} / \mathrm{Al}_{0.45} \mathrm{Ga}_{0.55} \mathrm{As}$ mid-infrared 3 QW-based quantum cascade laser emitting at $\sim 9 \mu \mathrm{m}$. The theoretical model is based on Schrodinger equation analysis. The increase in the doping densities creates a decrease of the peak gain value and furthermore the wavelength shift to the shorter wavelength. Accordingly any change in the wavelength can be not only by the variation of well thickness, but also one can get the available wavelength by changing the doping density.

A theoretical analysis shows decreased in the NDR when the doping density increased. This result refer to the available current rang before the occurrence of the NDR reduced when the doping density level decrease. 


\section{References}

1. R. Kazarinov and R. Suris, Sov. Phys. Semicond. 5, 707 (1971).

2. J. Faist, F. Capasso, D. L. Sivco, C. Sirtori, A. L. Hutchinson, and A. Y. Cho, Science 264, 553(1994).

3. C. Gmachl, A. Trediccuci, D. L. Sivco, A. L. Hutchinson, F. Capasso, and A. Y. Cho, Science 286, 749(1999).

4. C. Gmachl, D. L. Sivco, R. Colombelli, F. Capasso, and A. Y. Cho, Nature (London) 415, 883 (2002).

5. M. Beck, D. Hofstetter, T. Aellen, J. Faist, U. Oesterle, M. Ilegems, E. Gini, and H. Melchior, Science 295, 301(2001).

6. J. Y. Bengloan, A. De Rossi, V. Ortiz, X. Marcadet, M. Calligaro, I. Maurin, and C. Sirtori, Appl. Phys. Lett. 84, 2019 (2004).

7. C. Sirtori, P. Kruck, S. Barbieri, P. Collot, J. Nagle, M. Beck, J. Faist, and U. Oesterle, Appl. Phys. Lett. 73, 3486(1998).

8. K. Ohtani and H. Ohno, Jpn. J. Appl. Phys., Part 2 41, L1279 (2002).

9. R. Teissier et al., Appl. Phys. Lett. 85, 167 (2004).

10. D. G. Revin, L. R. Wilson, E. A. Zibik, R. P. Green, J. W. Cockburn, M. J. Steer, R. J. Airey, and M. Hopkinson, Appl. Phys. Lett. 85, 3992(2004).

11. R. Köhler et al., Nature _London_417, 156 (2002).

12. S. Barbieri, J. Alton, H. E. Beere, E. H. Linfield, and D. A. Ritchie, Appl. Phys. Lett. 85, 1674 (2004).

13. H. Page, C. Becker, A. Robertson, G. Glastre, V. Ortiz, and C. Sirtori, Appl. Phys. Lett. 78, 3529 (2001).

14. D. A. Carder, L. R. Wilson, R. P. Green, J. W. Cockburn, M. Hopkinson, M. J. Steer, R. Airey, and G. Hill, Appl. Phys. Lett. 82, 3409 (2003).

15. V. Ortiz, C. Becker, H. Page, and C. Sirtori, J. Cryst. Growth 251, 701 (2003).

16. D. Indjin, S. Höfling, A. Mirčetić, V.D. Jovanović1, J. Radovanović, Z. Ikonić, N. Vukmirović, P. Harrison, V. Milanović, J. P. Reithmaier and A. Forchel, Materials Science Forum, 518, 29 (2006).

17. E. A. AL-Dabbagh, Ph. D. Thesis, University of Mosul, College of Education, 2005.

18. V. D. Jovanovic, Journal of Applied Physics, 99, 103106(2006).

19. D. Indjin, P. Harrison, R. W. Kelsall, and Z. Ikonić, Applied Physics Lett. 81, 400(2002). 